\title{
Mastitis Incidence in First-Calf Heifers on the Small Farms of the Republic of Armenia
}

\author{
Zh.S. Melkonyan, V.V. Khotsanyan, K.A. Sukiasyan, E.A. Nikoghosyan \\ Armenian National Agrarian University \\ zhanna.smelkonyan1@gmail.com, vrezhvk@gmail.com, karinesukiasyan58@gmail.com, erik-nik69@yandex.ru
}

\section{A RT I CLE I N F O}

\section{Keywords:}

first-calf heifer,

mastitis,

udder,

dimastin,

preventive treatment

\begin{abstract}
A B S T R A C T
The article presents the results of scientific research aimed at studying mastitis incidence in first-calf heifers and the affection of udder quarters in the mastitic first-calf heifers on eleven small farms in the Kotayk and Ararat regions of Armenia.
\end{abstract}

According to the results of scientific research, subclinical mastitis incidence in first-calf heifers made $32.3 \%$, while the number of affected udder quarters was 78 (per 100 animal units). The clinical mastitis was diagnosed in $10.7 \%$ of firstcalf heifers and the number of affected udder quarters was 25 .

Upon the research results, the experimental farms were provided with practical recommendations on prevention of mastitis in first-calf heifers.

\section{Introduction}

Bovine mastitis is considered as $\mathrm{N} 1$ problem in the contemporary dairy farming. This disease causes serious economic damage to the industry. Sharp drop in milk quality and yield is recorded due to mastitis (Parikov, 2000, Logvinov, 1992).

According to statistical data, each year 50 percent of animals are affected by the subclinical bovine mastitis, while 20-25 percent of animals manifest clinical inflammation of udder (Bogush, et al., 2001).

Mastitis may affect a cow at any age but more often it occurs in the first-calf heifers, especially during the first 3 months of lactation, and the morbidity rate of decease is very high - up to $66.6 \%$ - which poses threat to the animal health and often causes an untimely death of cows (Konopeltsev, 2010).

Proceeding from the above, it can be stated that the scientific research aimed at identification and treatment of the mastitis in first-calf heifers is still important nowadays (Bogush, 2009).

\section{Materials and methods}

Research activities for the assessment of mastitis incidence in brown Caucasian first-calf heifers were carried out in the laboratories of the Research Center for Veterinary Medicine and Veterinary Sanitary Examination at the 
Armenian National Agrarian University, as well as on eleven small farms of the Kotayk and Ararat regions in the Republic of Armenia. Management methods of animals were stall barn housing (stabling) and grazing.

We pursued a goal in 2020, to study the incidence of clinical and subclinical mastitis in first-calf heifers, as well as identify the rate of mastitis affecting the udder quarters.

Initially, the animal housing, feeding and health conditions, as well as the lactiferous gland and secretion quality of first-calf heifers were studied on each farm. Symptoms peculiar to mastitis were identified based on the medical history and general work-up of the first-calf heifers, while the examination of udder - by milking a secretion therefrom.

The milk was tested by using $5 \%$ dimastin solution and the special-purpose milk testing plates containing four hemispherical slots with black-and-white counterstains and circular grooves corresponding to $1 \mathrm{ml}$ and $2.5 \mathrm{ml}$ volumes of milk. Each slot was poured in with $1 \mathrm{ml}$ milk from the respective quarter of udder and supplemented with $1 \mathrm{ml}$ dimastin from the automatic beak bottle. The mixture of milk and reagent was stirred with a stick for 30 seconds. The response was recorded with crisscrosses based on the jellium density, while the color change served as a benchmarking and tiebreaking indicator. The jellium density reaction was recorded as follows: if a homogeneous liquid was produced, then the response was considered as negative (-). Where the traces of jellium were available in liquid, the response was considered as doubtful $( \pm)$. Wherever coagulate was clearly visible and popped out of the slot in half or completely, the response was considered as positive $(+++)$.

If orange or orange-red color of milk appeared upon treating with dimastin, a normal subacidic response was observed. Yellow color was an indication of increased acidity, the red color indicated an alkalinity shift, and the scarlet, carmine and magenta colors - an increased alkalinity in milk.

Upon the registration of milk test results, the content of slots was poured out into a bucket, and the plate was rinsed with clean warm water in another bucket and wiped dry with a towel.

For each testing, a list of first-calf heifers was compiled indicating the farm, date of test and cow ID number.

In order to verify the latent mastitis diagnosis, the milk taken from the udder quarter which manifested a positive response to dimastin during the test, was additionally tested for sedimentation as follows:
Upon milking the cows, $10-15 \mathrm{ml}$ of milk from each udder quarter was poured into tubes and put into refrigerator for $16-18$ hours at the temperature of $4-10^{\circ} \mathrm{C}$. On the second day, the results were examined in the light. While examining the milk during the sedimentation test, the key attention was paid to the sediment. Healthy cows shall have white milk without any sediment. In the cows affected with mastitis a sediment was available at the bottom of test tubes, indicating their positive response for mastitis; and wherever the sediment thickness was over $0.1 \mathrm{~cm}$ then such cows were considered as sick.

\section{Results and discussions}

The research results demonstrated that the subclinical mastitis had affected 21 of 65 tested first-calf heifers, which makes $32.3 \%$ if converted to 100 first-calf heifers. Seven cows $(10.7 \%)$ out of 65 had a clinical mastitis of varying severity (Table 1).

Table 1. Incidence rate of subclinical and clinical mastitis in the first-calf heifers*

\begin{tabular}{|c|c|c|c|c|c|}
\hline \multirow[b]{2}{*}{$\begin{array}{c}\text { Farm } \\
\text { No. }\end{array}$} & \multirow[b]{2}{*}{ 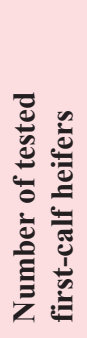 } & \multicolumn{2}{|c|}{$\begin{array}{l}\text { Positive response for } \\
\text { subclinical mastitis }\end{array}$} & \multicolumn{2}{|c|}{$\begin{array}{l}\text { Positive response } \\
\text { for clinical mastitis }\end{array}$} \\
\hline & & 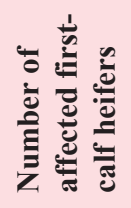 & $\%$ & 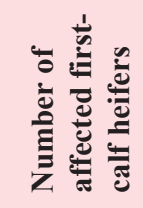 & $\%$ \\
\hline 1 & 5 & 2 & 40 & - & - \\
\hline 2 & 15 & 4 & 26.6 & 2 & 13.3 \\
\hline 3 & 6 & 2 & 33.3 & 1 & 16.7 \\
\hline 4 & 3 & 1 & 33.3 & - & - \\
\hline 5 & 2 & 1 & 50.0 & 1 & 50.0 \\
\hline 6 & 4 & 2 & 50.0 & 1 & 25.0 \\
\hline 7 & 2 & - & - & - & - \\
\hline 8 & 10 & 3 & 30 & 1 & 10.0 \\
\hline 9 & 5 & 1 & 20 & - & - \\
\hline 10 & 4 & 2 & 50 & - & - \\
\hline 11 & 9 & 3 & 33.3 & 1 & 11.1 \\
\hline Total & 65 & 21 & 32.3 & 7 & 10.7 \\
\hline
\end{tabular}

*Composed by the authors. 
Table 2. First-calf heifers affected with subclinical and clinical mastitis per the udder quarters*

\begin{tabular}{|c|c|c|c|c|c|c|c|c|c|c|c|c|c|c|c|}
\hline \multirow{2}{*}{$\begin{array}{c}\text { Farm } \\
\text { No. }\end{array}$} & \multicolumn{2}{|c|}{$\begin{array}{l}\text { Total number of tested } \\
\text { first-calf heifers }\end{array}$} & \multicolumn{6}{|c|}{ Subclinical mastitis } & \multicolumn{7}{|c|}{ Clinical mastitis } \\
\hline & $\begin{array}{l}\text { Number } \\
\text { of animals }\end{array}$ & $\begin{array}{l}\text { of which the } \\
\text { number of } \\
\text { sick animals }\end{array}$ & Fl & $\mathrm{Fr}$ & HI & $\mathrm{Hr}$ & Total & • & $\begin{array}{c}\text { Number } \\
\text { of sick } \\
\text { animals }\end{array}$ & Fl & $\mathrm{Fr}$ & HI & $\mathrm{Hr}$ & $\begin{array}{c}\text { Total number } \\
\text { of udder } \\
\text { quarters }\end{array}$ & $\bullet$ \\
\hline 1 & 5 & 2 & 1 & - & 1 & 1 & 3 & 60 & - & - & - & - & - & - & - \\
\hline 2 & 15 & 4 & 1 & 2 & 1 & 2 & 6 & 40 & 2 & 1 & 2 & 2 & 2 & 7 & 47 \\
\hline 3 & 6 & 2 & 1 & 2 & - & 2 & 5 & 83 & 1 & 1 & - & 1 & 1 & 3 & 50 \\
\hline 4 & 3 & 1 & - & 1 & 1 & 1 & 3 & 100 & - & - & - & - & - & - & - \\
\hline 5 & 2 & 1 & 1 & - & 1 & 1 & 3 & 150 & 1 & 1 & - & 1 & 1 & 3 & 150 \\
\hline 6 & 4 & 2 & 1 & - & 1 & 2 & 4 & 100 & 1 & - & 1 & 1 & 1 & 3 & 75 \\
\hline 7 & 2 & - & - & - & - & - & - & - & - & - & - & - & - & - & - \\
\hline 8 & 10 & 3 & 2 & 1 & 2 & 3 & 8 & 80 & 1 & 1 & 1 & 1 & 1 & 4 & 40 \\
\hline 9 & 5 & 1 & 1 & - & 1 & 1 & 3 & 60 & - & - & - & - & - & - & - \\
\hline 10 & 4 & 2 & 1 & 2 & 2 & 2 & 7 & 175 & - & - & - & - & - & - & - \\
\hline 11 & 9 & 3 & 2 & 2 & 3 & 2 & 9 & 100 & 1 & 1 & - & 1 & 1 & 3 & 33 \\
\hline Total & 65 & 21 & 11 & 10 & 13 & 17 & 51 & 78 & 7 & 5 & 4 & 6 & 7 & 23 & 35 \\
\hline
\end{tabular}

Note: •- affected udder quarters converted to 100 first-calf heifers. Udder quarters (Fl - front left, $\mathrm{Fr}$ - front right, $\mathrm{Hl}$ - hind left, $\mathrm{Hr}$ hind right)

*Composed by the authors.

As it can be noticed from the data of Table 1, the minimum incidence of subclinical mastitis in first-calf heifers was detected on the ninth farm, while the maximum incidence - on the 5th, 6th and 10th farms. For clinical mastitis, the incidence was minimum $(10 \%)$ on the eighth farm and maximum $(50 \%)$ on the fifth farm. Zero incidence of both subclinical and clinical mastitis was detected on the seventh farm; and no clinical mastitis was detected on the first, fourth, seventh, ninth and tenth farms.

In the course of research, we also aimed to assess incidence of subclinical and clinical mastitis affecting the udder quarters in first-calf heifers. Research data are presented in Table 2.

Table 2 demonstrates the affection of different udder quarters during the clinical and subclinical inflammation. The number of udder quarters affected by subclinical mastitis in first-calf heifers was 78 per 100 animal units. The extreme values ranged from 40 udder quarters on the second farm to 175 quarters on the tenth farm. As regards the clinical mastitis, 35 quarters were affected (ranging from 33 to 150). The maximum affected udder quarters were observed on the 5 th farm. It is apparent from Table 2 , that as regards the clinical mastitis, there is a higher rate of affection of hind left and hind right quarters
(20\% and $26.5 \%$ ), which is most likely associated with the peculiarities of cows lying on their right side. These quarters closely contact with floor and they are closer to the manure passage.

Mastitis can be prevented on the farms if following the hygiene rules. However, there are diverse predisposing causes of mastitis in the first-calf heifers. As a result of our studies on housing and feeding conditions in first-calf heifers, we proposed the following preventive measures for the targeted farms: provision of clean and dry place of housing, weekly disinfection of cubicles, obligatory control of flies, timely removal of manure at least 500 $\mathrm{m}$ away from the farm, disinfection of udder before and after milking, wiping the teats (one wipe per each cow), scrubbing the milkers' hands with disinfecting solution, no feeding calves with mastitic milk, isolation of firstcalf heifers from the sick cows, keeping the milking order (first-heifers - healthy cows - cows with sick udder) and timely treatment of wounds, injuries and lacteous gland.

\section{Conclusion}

Results of the research performed on the abovementioned farms enable to conclude that during the clinical and 
laboratory tests, the subclinical mastitis incidence in the first-calf heifers made $32.3 \%$, and the clinical mastitis incidence - $10.7 \%$.

Studies revealed that the amount of udder quarters was 78 quarters per 100 first-calving heifers affected with a subclinical mastitis, and 25 quarters per 100 first-calving heifers - affected with a clinical mastitis.

Upon the examination of the first-calf heifers' housing and feeding conditions, we identified the predisposing and immediate causes of mastitis and provided the practical recommendations to the maintenance personnel of experimental farms.

\section{References}

1. Bogush, A.A (2009). Cow Mastitis and its Prevention Measures / A.A. Bogush, V.E. Ivanov, L.M. Borodich.

- Minsk: LLC "Belproject”, - 160 p. (in Russian).
2. Bogush, A.A., Ivanov, V.E., Golynets, V.G. (2001). Mastitis Incidence in Cows on Livestock Farms // Veterinary Medicine of Belarus, - No1, - pp. 39-40 (in Russian).

3. Konopeltsev, I.G. (2010). Inflammation of the Udder in Cows / I.G. Konopeltsev, V.N. Shulyatiev. - Kirov, St. Petersburg: SPbGAVM, - 355 p. (in Russian).

4. Logvinov, D.D. (1992). Mastitis and Milk Quality / D.D. Logvinov // Dairy and Beef Cattle Breeding, - No 5, - p. 6 (in Russian).

5. Parikov, V.A. (2000). Results and Prospects of Research on the Fight against Cow Mastitis (Etiology, Diagnostics, Prevention and Therapy) / V.A. Parikov // Theoretical and Practical Aspects of the Emergence and Development of Animal Diseases and the Protection of their Health in Contemporary Conditions: Mater. Int. Conf., Voronezh, - V. 1, - pp. 197-202 (in Russian). 